\title{
REALISMO Y ESPACIO URBANO: NOTAS SOBRE LA TRIBUNA DE EMILIA PARDO BAZÁN
}

\author{
Dolores THION SORIANO MOLLÁ \\ Université de Pau et des Pays de l'Adour
}

\section{RESUMEN}

A través del presente trabajo se pretende demostrar que el espacio, en La Tribuna de Emilia Pardo Bazán, desempeña un papel preponderante en el establecimiento del pacto de ficción para que la novela sea actualizada como intencionalmente realista. El estudio de los paratextos, del incipit, del primer capítulo y del diseño de La Tribuna pone de manifiesto que el espacio urbano otorga cohesión y unidad al conjunto de cuadros y estudios que componen la novela, como elemento estructurante y estético en el que se sustenta el determinismo naturalista.

Palabras clave: Realismo, Naturalismo, Espacio, Novela urbana, La Tribuna, Emilia Pardo Bazán, Incipit.

\section{ABSTRACT}

This paper aims to show that the concept of space in La Tribuna of Emilia Pardo Bazán is paramount to the establishment of the fictional pact that is required for the novel to be revised as intentionally realistic. The study of the paratexts, the incipit, the first chapter and the design of La Tribuna underscores the fact that the urban space gives cohesion and unity to the ensemble of scenes and studies that make up the novel, as a structuring and aesthetic element, and a cornerstone its naturalist determinism.

Key words: Realism, Naturalism, Space, Urban roman, La Tribuna, Emilia Pardo Bazán, Incipit.

El reconocimiento por parte del lector de las coordenadas referenciales es una de las condiciones sine qua non para que el texto sea actualizado como intencionalmente realista (Villanueva, 1992 y 2004). El mundo posible en el que 
programáticamente se entreteje una novela realista proporciona al lector de manera inmediata toda la información necesaria para que el relato se ajuste a un universo de ficción construido en unos espacios y regido en unos tiempos organizados de acuerdo con la lógica, los atributos y las funciones naturales de las experiencias vividas por el lector coetáneo; o en otros términos, para la creación «del campo interno de referencia y la producción de garantías de autenticidad» (Villanueva, 1992: 181). Los escritores, conscientes de la necesidad de seducir a su lector desde sus primeros contactos y de responder a su horizonte de expectativas, suelen utilizar los recursos del paratexto -retomando la terminología de Genette- y, como demuestra Darío Villanueva en su fundamental estudio Teorías del Realismo, en el «título, el primer párrafo y el capítulo inicial de la obra sometida a la prueba de su productividad realista como textos básicos sobre cuyas propiedades estructurales y estilísticas se habrá de comprobar la respuesta del lector o lectores» (Villanueva, 1992: 181).

En este trabajo nos detendremos además en el estado de la funcionalidad de otros elementos tales como el índice de títulos, los incipit de los capítulos y el diseño estructural de la obra en cuadros-secuencias. Observaremos cómo el espacio de la urbe -y la calle como unidad metonímica- otorgan cohesión y favorecen la plasmación de los preceptos estéticos naturalistas.

Emilia Pardo Bazán en La Tribuna (1883) hizo uso de todos estos componentes narrativos para establecer un pacto de ficción realista y explorar las estrategias que permitían plasmar su personal lectura de la estética naturalista.

\section{LOS PARATEXTOS DE LA TRIBUNA: UN PROGRAMÁTICO TEXTO REALISTA}

El título anuncia una novela de personaje tan en boga a la sazón. Aunque en Amparo, la Tribuna, recaiga un peso fundamental en la construcción del mundo de ficción verosímil, nos centraremos en el estudio de la dimensión espacial ya que es uno de los componentes, que de entrada guía al lector en el proceso de desentrañamiento del texto y, por lo tanto, uno de los elementos que en primer término se suele someter a la «prueba de productividad realista» para que su lectura sea intencionalmente, valga la redundancia, realista. Por la fusión natural del espacio con la dimensión temporal -el cronotopo de Batjin- en el desarrollo de la trama o por las relaciones simbióticas que entabla con el personaje, asociaremos estas coordenadas y componentes cuando lo consideremos imprescindible.

Antes de adentrarnos en el estudio del incipit y del primer capítulo de la novela como unidades productoras de sentido de realidad en el establecimiento del pacto de ficción, detengámonos en otros de los componentes 
del paratexto que cumple semejantes funciones. Se trata del prólogo de la novela, estrategia a la que solía recurrir en este período Emilia Pardo Bazán para exponer sus planes estéticos (Patiño Eirín, 1995). En el de la La Tribuna la escritora justifica algunas de sus elecciones y las referidas a Marineda, la ciudad literaria, son de singular importancia para el estudio de la dimensión espacial en la creación del pacto de ficción novelesco.

Emilia Pardo Bazán, guiada por los límites que imponen una «trama de sucesos políticos tan recientes como la Revolución de Setiembre de 1868» (Pardo Bazán, 2002: 47) transcurridos en la ciudad de La Coruña, recurrió en La Tribuna al prólogo para justificar su quehacer novelesco. La factura imaginativa de sus geografías, y no sólo morales como la escritora aducía en su manuscrito, le « impulsó a no situarla en ningún punto de la geografía física, sino de aquella geografía moral de que habla Pereda, y que todo novelista se forma en uso del más indiscutible de los derechos» (Bernardi, 2007: 159). En el manuscrito original de ese programático prólogo, la escritora optaba por elucidar en qué consistía su estética, parcialmente realista-naturalista por decisión propia, al igual que hizo en otras novelas:

Así ni en el terreno privado ni en el político podría decirse que aunque el fondo está tomado en el riquísimo campo de la realidad, he prescindido de aquella libre invención que el novelista ha menester y a la vez que ha tenido más libertad para fijar con [¿razón?] de la verdad el palacio de la fantasía (Bernardi, 2007: 160).

Aunque Emilia Pardo Bazán estudiaba la realidad circundante, mantenía su relato en las lindes de la ficción verosímil ya que éstos le conferían mayor libertad para «dar vida a un análisis» (Bernardi, 2007: 160) que de manera objetiva había realizado previamente. Ese justo medio en el que deseaba establecer La Tribuna, pese a su significativa importancia, quedó algo eclipsado en la versión final de aquellas advertencias. En ella, la autora dilataba su justificación en un preciso pasaje en el que equiparaba la geografía física de la ciudad de Marineda con la de otras ciudades de existencia literaria, precisamente porque uno de los componentes que más ayudan al lector a aferrarse a la realidad es el espacio, si bien puede resultar un lastre para la creatividad del escritor. Por dichas razones, en el prólogo definitivo doña Emilia justificó con mayor detalle sus argumentos iniciales y recomendó a su lector ideal que se recrease su propio y ficticio espacio urbano:

Quien desee conocer el plano de Marineda, búsquelo en el atlas de mapas y planos privados, donde se colecciona, no sólo el de Orbajosa, Villabermeja y Coteruco, sino el de las ciudades de $\mathrm{R}^{* * *}$, de $\mathrm{L}^{* * *}$ y de $\mathrm{X}^{* * *}$, que abundan en las novelas románticas. Este privilegio concedido al novelista de crearse un mundo suyo propio, permite más libre inventiva y no se opone a que 
los elementos todos del microcosmos estén tomados, como es debido, de la realidad. Tal fue el procedimiento que empleé en La Tribuna, y lo considero suficiente -si el ingenio me ayudase- para alcanzar la verosimilitud artística, el vigor analítico que infunde vida a una obra (Pardo Bazán, 2002: 47).

En esos términos definía la escritora el marco topográfico en el que se desarrolla la historia narrativa de La Tribuna. De hecho, los lugares que habitan o recorren los personajes se integran con verosimilitud en la unidad urbanística de la ciudad, en sus componentes arquitectónicos - casas, fábrica, iglesias, plazas, paseo, teatro y castillo-, en su vías de comunicación -calles y carreteras-, en sus organizaciones y divisiones en barrios altos y bajos, en el centro de la ciudad y sus parajes naturales circundantes -huerto, playa, alameda-, en el núcleo y el periférico mundo rural. Sin embargo, la protección de los acontecimientos y de los personajes que habitaban Marineda bajo el casi translucido velo de la ficción le servía de salvaguarda ante cualquier ejercicio de verificación en el que hubiesen podido explayarse sus convecinos de La Coruña. Los aspectos políticos y morales de la novela justifican en aquella Coruña decimonónica las precauciones que tomaba doña Emilia. Precisamente, ya se ha estudiado la dimensión espacial de las obras localizadas en las ciudades de su Galicia y se ha analizado cómo en La Tribuna la autora recreaba su ciudad natal bajo el nombre de Marineda, al igual que lo hizo en De mi tierra (1888), en La piedra angular (1891), en Doña Milagros (1894), en Memorias de un solterón (1896) y en las novelas cortas La dama joven y Rodando (Levy 19591961, págs. 283-284). Como afirmaba Benito Varela Jácome, en ellas «Marineda es más que un símbolo de prototípica ciudad provinciana. Es una realidad ciudadana concreta, recognoscible en sus menores elementos urbanos, a pesar de los cambios de nombre de sus barrios, sus calles y sus plazas» (Varela Jácome, 1973: 166). El lector coruñense o allegado a dicha urbe podía actualizar y descubrir los referentes realistas de la novela que compondrían, pese a lo afirmado por la escritora, su campo de referencia externo y establecer sus personales reglas de autentificación realista. Ese lector podía, sin grandes dificultades, identificar los lugares novelados, los barrios, las calles, las plazas y los monumentos... en los años de transcurso de la novela y cotejarlos con los existentes, como ya lo hicieron Josette Lévy y Benito Varela Jácome. En ese plano literario de Marineda, el lector local, sobre todo coetáneo, podría identificar sin grandes dificultades lo que en los siguientes términos exponía Varela Jácome:

El Barrio Alto es la Ciudad Vieja; el Barrio Bajo, la Pescadería. El «Páramo de Solares» separa los dos núcleos urbanos. El antiguo «Derribo» corresponde a la actual calle empinada de Nuestra Señora del Rosario; el campo de San Agustín se transforma más tarde en plaza del Marqués de San Martín [...] En 
el ámbito de la Pescadería, la «Calle Mayor», principal vía de enlace entre los sectores alto y bajo, es la actual Calle Real. La asoportalada Marina, surgida como consecuencia del relleno para la construcción figura con su verdadero nombre. El «Paseo de Filas» es el Cantón. El bullicioso mercado está localizado en el mismo lugar: Y la calle de Cartuchos, entre Panaderas y de San Agustín, se llama, desde 1916, de Varela Silvela.

La descripción de la iglesia de «San Efrén», cita de la burguesía coruñera, es sin duda alguna, la parroquial San Jorge. [...] En el cinturón ciudadano del sur, la Olmeda corresponde a la Palloza, y la «Cuesta de San Hilario», a Santa Lucía. En el extremo montaraz de la península podemos marcar varios itinerarios: los alrededores del cementerio; la actual calle del Faro; la vereda del polvorín; la Ronda de Monte Alto; el camino de la Torre de Hércules; desde el Campo de Marte a Las Lagoas, denominada Avenida de Hércules desde 1929... (Varela Jácome, 1973: 167-168).

Aun cuando los dictados de la escritora relativos a la ciudad quedaban claramente establecidos, su ocultamiento resultaba en realidad liviano, como bien demostraba Varela Jácome en la extensa cita reproducida.

Si consideramos otros paratextos como semilleros de sentido que potencialmente podían corroborar el realismo de La Tribuna, cabría -antes de adentrarnos en el estudio del espacio en el incipit y en el primer capítuloexaminar el índice de títulos, paratexto con el que la escritora estimula la curiosidad, nutre el horizonte de expectativas del lector y refuerza la trabazón de la novela. Aun cuando Emilia Pardo Bazán otorgaba gran relevancia al marco geográfico, el espacio ya no sobresale en la titulación de los capítulos con aquella singularidad que en el prólogo le atribuía. Sólo dos títulos remiten a lugares o escenarios: «Pueblo de su nacimiento» (III) y «Dónde vivía la protagonista» (XXX). Ambos ponen de manifiesto la relevancia del espacio en tanto que tema y base filosófica en la novela naturalista. Más tarde volveremos sobre el asunto.

Por otra parte, anotemos que predomina la titulación sustantiva sobre la verbal. Emilia Pardo Bazán seleccionaba cosas varias - «Barquillos» (I), Villancicos de Reyes (V), «Pitillos» (XI), «Estudios históricos y políticos» (X), «Sorbete» (XIV)-; anunciaba funciones de los personajes - «Padre y madre» (II), «Tribuna del pueblo» (XVIII)...- o introducía referentes históricos -«La Gloriosa» (IX), «Himno de Riego, Garibaldi, Marsellesa» (XV), «Revolución y reacción mano a mano» $(\mathrm{XVI}) . . .-$. El esquematismo dominante no es óbice para que estos títulos no cumplan las funciones informativas, conativas y poéticas que les son propias, ya que todos obedecen a realidades que forman parte de las descripciones de ambientes o de los relatos de hechos. Numerosas titulaciones de La Tribuna responden al modelo de descripción realista-naturalista en la que incluso el objeto más nimio puede dinamizar un significado 
metonímico. En última estancia, la titulación de los capítulos en La Tribuna revela su condición de estudios o documentos ensamblados «de una manera objetiva, documental, ofreciéndolos como pequeños conjuntos orgánicos, que en apariencia apenas presentan conexión unos con otros» (Baquero Goyanes, 1986: 11).

En el marco pragmático global de la novela, antes de iniciar la lectura del texto creativo, el lector ya poseía las reglas que la escritora establecía para la construcción de su universo ficcional y algunas claves para su desentrañamiento que estimulasen la suspensión del juicio, en particular las del lector coruñense y coetáneo. Todos estos elementos se revalidan desde el incipit del texto -a menudo coincidente con el primer párrafo citado por Darío Villanueva- en los primeros contactos efectivos del receptor con el universo de ficción.

Frente al concepto tradicional latino Incipit liber, o primera frase de un libro, Yuri Lotman (1988) estudió la presencia del marco como frontera que separa la obra literaria de todo lo que está fuera de ella y analizó su función codificadora. La delimitación de incipit ha generado opiniones muy diversas. Aunque todos suelen destacar su papel como generador de sentido, su delimitación es muy imprecisa, de la primera frase (Duchet, 1971 y 1980) o la primera escena (Dubois, 1973) a interpretaciones más flexibles que proponen una geometría variable, como la de Andrea del Lungo $(1997,2003)$. Para Del Lungo, la extensión del incipit depende del tipo de texto y de sus funciones. Por consiguiente, lo define como un fragmento de texto que se sitúa en el umbral de entrada al universo de ficción -en el que un narrador ficticio toma la palabra para dirigirse a un lector ficticio- y se cierra en la primera ruptura importante del texto. Este fragmento mantiene relaciones estrechas con el paratexto y el resto del texto, cumple las funciones de referente y orientador, establece un primer acuerdo con el que se relacionará el resto de la obra (Del Lungo 2003: 54-55).

\section{EN TORNO AL INCIPIT Y EL PRIMER CAPÍTULO}

El incipit de La Tribuna corresponde a las características del texto básico capaz de suscitar respuestas positivas en los lectores que se adentren en el universo de ficción. Pardo Bazán dispuso en un orden bastante clásico los componentes novelescos esenciales. El espacio, el tiempo, el personaje y la acción enmarcan el texto en unas coordenadas verosímiles según se puede observar en la cita siguiente:

Comenzaba a amanecer, pero las primeras y vagas luces del alba a duras penas lograban colarse por las tortuosas curvas de la calle de los Castro cuando 
el señor Rosendo, el barquillero que disfrutaba de más parroquia y popularidad en Marineda, se asomó, abriendo a bostezos, a la puerta de su mezquino cuarto bajo. Vestía el madrugador un desteñido pantalón grancé, reliquia bélica, y estaba en mangas de camisa. Miró al poco cielo que blanqueaba por entre los tejados, y se volvió a su cocinilla, encendiendo un candil y colgándolo del estribadero de la chimenea. Trajo del portal un brazado de astillas de pino, y sobre la piedra del fogón las dispuso artísticamente en pirámide, cebada por su base con virutas, a fin de conseguir una hoguera intensa y flameante. Tomó del vasar un tarterón, en el cual vació cucuruchos de harina y azúcar, derramó agua, cascó huevos y espolvoreó canela. Terminadas estas operaciones preliminares, estremeciose de frío -porque la puerta había quedado de par en par, sin que en cerrarla pensase y descargó en el tabique dos formidables puñadas. (cap. I, 51) ${ }^{1}$

Emilia Pardo Bazán introduce al lector con este incipit narrativo en su universo novelesco bajo la perspectiva de un narrador omnisciente, quien transcribe la materialidad de la escena observada con aparente fidelidad y objetividad. El narrador supuestamente selecciona la información necesaria para que aquel universo sea reconocido como verosímil. El incipit se estructura en dos partes. En la primera, se establecen los referentes iniciales del texto: tiempo, espacio y personaje. Las coordenadas temporales y espaciales yuxtaponen dos niveles informativos, el general o universal y el particular: cualquier amanecer y sus primeras luces, de cualquier calle «de los Castros» y cualquier cuarto bajo que el lector conoce de antemano y acepta como elementos del campo de referencias del universo literario marinedino. En este párrafo inicial la escritora aporta por lo tanto la información mínima sobre su universo de ficción y anuncia su proyecto de creación artística. A pesar de la aparente objetividad, el narrador utiliza un lenguaje poético con adjetivos y adverbios, con luces y formas que condicionan la percepción pictórica del escenario -sucinta pero eficazmente descrito- en el que sumerge al personaje. Las pinceladas descriptivas de la oración inicial despliegan significados connotativos que enriquecen las atmósferas contrastadas y en oposición -oscuridad y luz, frío y calor- del marco. Este se presenta ya en constituyentes mínimos del paisaje urbano: calle, ciudad, casa, tejados, chimenea, puerta, tabique combinando vistas exteriores e interiores, habitadas y vacías, públicas y privadas, que anticipan la singularidad de la novela por ubicarse en las clases bajas de la sociedad y reflejar su problemática condición en el seno de Marineda. Además, por el medio en que el personaje del señor Rosendo se desenvuelve, por su apariencia externa, por su oficio y por la relación de sus acciones y gestos a los

1. Citamos siempre por la misma edición de La Tribuna de 2002 a cargo de Marisa Sotelo, pero a partir de ahora, indicaremos sólo el capítulo y la página.

Anales, 24, 2012, pp. 195-213 
que dedica la segunda parte del incipit, la escritora vuelve a insertar La Tribuna en el ámbito de la estética naturalista. Así queda instaurado el paradigma que determinará posteriormente a su protagonista -y no sólo por la pobreza y por los lugares que la caracterizarán o por los que transitará en la urbe-, porque será, a imagen de su padre, el personaje que «disfrutaba de más parroquia y popularidad en Marineda», capaz de sobrepasar las fronteras cerradas de su universo natural para contactar con los de las clases superiores sin por ello cambiar de condición. El ritmo vivo, la sintaxis y el vocabulario sencillos son otros elementos del relato de los que el incipit da cuenta. En suma, en su habilidoso párrafo inicial, doña Emilia abre las puertas de su universo de ficción con suma eficacia retórica y funcional, al punto que tanto los referentes como el establecimiento del proyecto estético encauzan incluso al lector despistado.

Dada la breve extensión de sus capítulos, el resto del primero sirve para completar la información del incipit. En él, el narrador redondea la descripción de la fabricación de barquillos en el que colabora la protagonista -una huraña y pobre «mozuela de hasta trece años» en cuya caracterización se demora- e introduce al tercer miembro de la familia, la madre paralítica y desdeñosa; todo ello en el espacio cerrado de la mísera casa. En armonía con el espacio en el que habita, el perfil de Amparo queda delineado de manera conductista merced a la descripción de los vestidos, de su comportamiento y de sus declaraciones, en contraste con las perspectivas del narrador comentador y de su madre. Ésta, condenada al inmovilismo del espacio interior, ya caracteriza a su hija de manera antagónica en el intercambio dialógico del final del primer capítulo:

Viendo a la chiquilla vestida se escandalizó: ¿a dónde iría ahora semejante vagabunda?

-A misa, señora, que es domingo... ¿Qué volver con noche ni con noche? Siempre vine con día, siempre... ¡Una vez de cada mil! Queda el caldo preparadito al fuego... Vaya, abur.

Y se lanzó a la calle con la impetuosidad y brío de un cohete bien disparado (cap. I, 56).

\section{LA CALLE COMO ELEMENTO DE COHESIÓN Y «PATRIA»DE AMPARO}

En el diseño de un mundo verosímil en el que dar densidad corpórea a los personajes, Pardo Bazán utiliza la calle como unidad esencial de la geografía urbana. El espacio de la calle, que fija las coordenadas referenciales desde el incipit, contribuye a la creación de un significado reticular por los valores individuales y sociales que presagia la novela. Amparo, la niña vagabunda, 
que rauda huye del sofocante espacio familiar «con la impetuosidad y brío de un cohete bien disparado», cierra el primer capítulo y prefigura la mujer emancipada en el espacio público. Ensanchando y abriendo referentes, del privado al público, del cuartucho en la calle de los Castros a las perspectivas panorámicas de la ciudad, logrará Pardo Bazán dar progenitura a Amparo en simbiosis con la urbe. Si en este primer capítulo en el que se prefigura la novela, la escritora logra captar a su lector, éste tendrá que subordinarse a los planes que ella le imponga al dividir La Tribuna en secuencias. En efecto, la brevedad con la que diseña sus unidades-documentos dilatan la definición del perfil de «la hija de la calle» (cap. VI, 86), a los capítulos inmediatos como después analizaremos.

Las coordenadas establecidas en el pacto de ficción, sobre todo en el incipit y el primer capítulo, se perpetúan y desarrollan a través de la novela. La concentración del espacio en un referente estructurado como la ciudad contribuirá de manera específica a la creación de la cohesión interna y responderá al horizonte de expectativas ya creado en el lector. A la ilusión de veracidad que dimensión espacial -en estrecho diálogo con los demás componente- potencia en estas unidades paratextuales y textuales se suma además la valoración que el naturalismo hace del espacio desde un punto de vista ideológico y estético. El determinismo del medio, la concepción de espacios que subsuman a los personajes y el detallismo de sus descripciones como metonimias de esos ambientes a los que tanta importancia concedió Zola y de los que no renegó técnicamente Emilia Pardo Bazán -a pesar de su defensa del libre albedrío y sus reparos a la prolijidad descriptiva en La Cuestión palpitante-, caracterizan La Tribuna como primer ejercicio naturalista de la escritora (Baquero Goyanes, 1986; Clemessy, 1988; González Herrán, 1988 y 1989b; Sotelo Vázquez, 1992).

En ese laboratorio naturalista que La Tribuna representa, si a medida que avanza la lectura la geografía de Marineda se va construyendo en fusión de los personajes, es porque éstos, siguiendo los dictados de Zola, están caracterizados por su entorno urbano como anunciaba el primer capítulo y ratificaba en los siete siguientes. Pardo Bazán atribuye a Amparo una vivencia fisiológica de la calle, sentida como necesidad vital: «Al sentar el pie en la calle, Amparo respiró anchamente» (cap. III, 62) y descrita de manera orgánica, pues «sentía Amparo en las piernas un hormigueo, un bullir de la sangre, una impaciencia como si le naciesen alas a miles en los talones» (cap. II, 57), de modo que una vez atendidas las tareas caseras, «con rapidez de ave, se evadía de la jaula y tornaba a su libre vagancia por calles y callejones» (cap. II, 58). En simbiosis con su modo de vida en la urbe, a Amparo la caracterizan «instintos erráticos» 
(cap. II, 58) y acabará encarnando el individuo cuyo destino condiciona el entorno. Si años después Amparo sobresalía en Marineda, se debía a su « robustez, vencedora en la lucha con el medio ambiente, había crecido en razón directa de los mismos peligros y combates» (cap. XXVII, 204). Por lo tanto, Pardo Bazán utilizó la dimensión espacial en las primeras páginas de su novela para definir el pacto de ficción realista, pero, en particular, para dar cuerpo artístico al determinismo naturalista. Para la niña abandonada y solitaria, «la calle es la patria» (cap. VI, 86) y «su paraíso» (cap. II, 58) «terrenal» (cap. VI, 86). Por ser un espacio en el que se afirmara su identidad femenina, el narrador recoge en su relato la mirada que ella vierte del mismo. La calle, vista a través del temperamento de la protagonista según rezaba el precepto naturalista, es ante todo movimiento, desplazamiento y fuente de libertad. Debido a sus orígenes y a diferencia de las mujeres de otras clases sociales, Amparo, niña o joven, deambula sola sin necesidad de entablar más que superficiales y, una vez más, fisiológicos a corporales relaciones de alteridad y sociabilidad:

El gentío la enamoraba, los codazos y enviones la halagaban cual si fuesen caricias, la música militar penetraba en todo su ser produciéndole escalofríos de entusiasmo. Pasábase horas y horas correteando sin objeto al través de la ciudad, y volvía a casa con los pies descalzos y manchados de lodo, la saya en jirones, hecha una sopa, mocosa, despeinada, perdida, y rebosando dicha y salud por los poros de su cuerpo. Sola en casa con su padre, apenas este salía, ella le imitaba por no quedarse metida entre cuatro paredes (cap. II, 58).

Su infancia de andariega solitaria por las calles de Marineda legitima su carácter independiente, según un doble sentido de causalidad-efecto entre el determinismo ambiental y el temperamento. Con estas bases Amparo encarna un modelo de individualismo atípico a la sazón. Por haber sido independiente en el espacio público, podrá devenir «la cigarrera revolucionaria» (Sotelo, 2010).

En los primeros capítulos, la calle representa un lugar abierto y de tránsito; zona de circulación y de intercambio, la calle es también espacio de contrastes. Las calles de Marineda por las que suele deambular Amparo son activas y animadas en los barrios pobres de Abajo y en las zonas comerciantes; herméticas, frías y mortecinas en el barrio rico de Arriba; desafiantes en torno a la Calle Mayor o la Pescadería (Valera Jácome, 1973: 167-176). Con el paso de las estaciones, a raíz de los acontecimientos históricos y durante las celebraciones, estos núcleos se convierten en escenarios cambiantes y transfigurados. Para Amparo -en ello redundará la escritora-, la urbe está concebida como universo en la que se pone de manifiesto su pensamiento y su subjetividad y que prefiguran su carácter expansivo y soñador:

La calle le brindaba mil distracciones, de balde todas. Nadie le vedaba creer que eran suyos los lujosos escaparates de las tiendas, los tentadores de las 
confiterías, las redomas de color de las boticas, los pintorescos tinglados de la plaza; que para ella tocaban las murgas, los organillos, la música militar en los paseos, misas y serenatas; que por ella se revistaba la tropa y salía precedido de sus maceros con blancas pelucas el Excelentísimo Ayuntamiento. ¿Quién mejor que ella gozaba del aparato de las procesiones, del suelo sembrado de espadaña, del palio majestuoso, de los santos que se tambalean en las andas, de la Custodia cubierta de flores, de la hermosa Virgen con manto azul sembrado de lentejuelas? ¿Quién lograba ver más de cerca al capitán general portador del estandarte, a los señores que alumbraban, a los oficiales que marcaban el paso en cadencia? Pues, ¿y en Carnaval? Las mascaradas caprichosas, los confites arrojados de la calle a los balcones, y viceversa, el entierro de la sardina, los cucuruchos de dulce de la piñata, todo lo disfrutaba la hija de la calle. Si un personaje ilustre pasaba por Marineda, a Amparo pertenecía durante el tiempo de su residencia: a fuerza de empellones la chiquilla se colocaba al lado del infante, del ministro, del hombre célebre; se arrimaba al estribo de su coche, respiraba su aliento, inventariaba sus dichos y hechos.

¡La calle! ¡Espectáculo siempre variado y nuevo, siempre concurrido, siempre abierto y franco! No había cosa más adecuada al temperamento de Amparo, tan amiga del ruido, de la concurrencia, tan bullanguera, meridional y extremosa, tan amante de lo que relumbraba (cap. II, 58).

Por su asimilación con la urbe, «Amparo, hija de las calles de Marineda, ciudadana hasta la médula de los huesos» (cap. XII, 120) se condena a sí misma al apartarse de la ciudad en un oculto y caricaturesco locus amoenus, escenario de sus amores. Ella no logra cambiar su condición porque el amor y la ambición la sumirán en cervantino engaño.

Como se ha podido ir observando, en La Tribuna los espacios no son meros escenarios ni lugares de paso o de estancia, sino que son «figuras activas, espacios personalizados, vivientes, malignos o pasivos» (Gullón, 1979: 119) o metonimias de los personajes que los ocupan. Son además espacios psicológicos y simbólicos, cuyos valores refuerza la percepción proxémica de los mismos (Álvarez Méndez, 2007: 14).

\section{DISEÑO NARRATIVO Y FUNCIONALIDAD DE LA URBE}

Otro de los resultados que doña Emilia obtuvo en el laboratorio naturalista es el diseño estructural de La Tribuna. El que esté fragmentada en treinta y ocho capítulos cortos e independientes responde a la voluntad de la escritora de crear un nuevo plan dispositivo de factura naturalista, como ya apunta Baquero Goyanes. Difícil resulta por lo tanto admitir que la organización de los capítulos, por muy superficial que le parezca a doña Emilia, carezca de significado y aun cuando diez años después, al analizar El jardín de Berenice de Maurice Barrès, declarase que: «la originalidad de un libro consiste en la 
novedad y eficacia de su contenido intelectual o artístico, no en pueriles alambicamientos ni en que los capítulos estén divididos en secciones numeradas con letras griegas. Tampoco la sensibilidad en vanas palabras» (Pardo Bazán, 1973: 1071; Patiño Eirín, 1998: 202). Además, «es impensable», como anota Germán Gullón a propósito de Los Pazos de Ulloa, «que doña Emilia fuera simplemente una descuidada a la hora de narrar, inconsciente del hecho de que ciertas transiciones entre episodios parecen demasiado abruptas» (Gullón, 1990: 92). Los cuadros o secuencias narrativas que representan cada uno de los capítulos pueden parecer desligados o abruptos según el criterio desde el que se analice, desde el desarrollo de la trama, de las focalizaciones o del tiempo diegético, pero no ocurre lo mismo dentro de la estructura absorbente y unitaria que la ciudad representa. La trabazón de las secuencias que componen la novela se establece sobre todo merced a la función aglutinadora de la urbe y a la íntima relación que sus espacios mantienen con sus personajes en su caracterización y en el desenvolvimiento de la acción.

Independientemente de si Pardo Bazán estuviese respondiendo o no a las críticas de Clarín respecto de la débil estructuración de sus novelas anteriores (González Arias, 1992: 50; Penas Varela, 2003: 51-55), lo cierto es que cuando la escritora compone sus novelas más naturalistas modifica la estructura y la dispositio. Ateniéndonos a las unidades más visibles, la de los capítulos, anotemos que Pascual López (1879) y Un viaje de novios (1881) se componen de 12 y 14 capítulos respectivamente, mientras que en La Tribuna (1883) casi triplica el número de capítulos elevándolos a 38 , pero, como ya hemos observado, fragmentando la intriga en secuencias ambientales, en tranches de vie, de modo que incluso el cuadro costumbrista se puede insertar por su interés documental como instantánea, sin gran menoscabo para el conjunto. Siguiendo la misma tónica en la creación de breves pero numerosos documentos orgánicos, Emilia Pardo Bazán compondrá Los Pazos de Ulloa (1886) con 30 capítulos y La Madre Naturaleza (1887) con 37, todos ellos de corta extensión como en La Tribuna; mientras que tras el paréntesis de El Cisne de Vilamorta (1885) con 26 capítulos, la escritora empieza a modificar sus diseños compositivos reduciendo paulatinamente el número de cuadros documentales -ya en Insolación (1889) eran 22-, pero, singularmente a partir de Una cristiana (1890), que consta de 13 capítulos, hasta llegar a los 6 capítulos extensos -con escenas y pausas internas-, que componen La Quimera (1905) o los 7 de Dulce Dueño (1911). Aunque todo ello dependa de los asuntos y tramas, es evidente que en el período de mayor auge del naturalismo y pese a las controvertidas opiniones sobre las características técnicas singulares o no 
en España de la corriente estética francesa, Pardo Bazán está realizando sus propios experimentos con la novela.

Porque la noción de cuadro o escena que sustenta la novela es insuficiente para construir un relato perfectamente arquitrabado por los límites materiales que impone, como indicábamos a la hora de caracterizar el personaje de Amparo como hija de las calles de Marineda, la escritora se esmera en que todos los componentes narrativos participen activamente en el desarrollo de una unitaria trabazón, imagen del fluir verosímil de la vida misma, a la vez que sigue pergeñando en ofrecer las instrucciones concretas que estimulen un desentrañamiento realista y mantengan las bases del pacto de ficción.

Si bien cada capítulo-secuencia está refrendado por las relaciones de continuidad y de orden que mantiene con la trama novelesca, sus inicios -a modos de incipit- siguen enriqueciendo el campo de referencias interno. En ellos, la información espacial es la más constante y precisa -frente a la temporal y a los personajes-. En todo el libro sólo tres inicios de capítulo carecen de locativos, mientras que una decena se abren sin referencias temporales diegéticas o históricas. Por lo tanto, la mayoría de las secuencias cuenta desde el principio con su cronotopo, aunque la escritora solía fijar las escenas en el marco del día o en el tiempo interno con indefinidos determinantes². Del cotejo de todas las introducciones secuenciales, podemos concluir que las ocho primeras -en las que se perfila el perfil de Amparo en las calles de Marinedason mucho más precisas y establecen mayor cohesión entre ellas. La geografía urbana -calles, casas y en mero grado, fábrica y paseo- y el fluir del tiempo diegético está más concentrado -un año y medio de intensas implicaciones autobiográficas-, entre un domingo de marzo de 1867 y septiembre de 1868, como ha demostrado el profesor José Manuel González Herrán en su estudio todavía inédito «Historia, ficción y biografía en La Tribuna (1883), de Pardo Bazán: Emilia y Amparo, entre 1867-1873»³. De hecho, la cohesión secuencial que caracteriza los primeros capítulos permite contrarrestar la imprecisión del tiempo histórico -retardada hasta el capítulo IX, «La Gloriosa»-como él mismo ya señalaba.

Tan pronto como Pardo Bazán proporciona a su lector la información necesaria en relación con los componentes narrativos, también a partir del capítulo IX, empieza a diversificar con mayor libertad creativa los espacios en los inicios de los capítulos. No obstante, la escritora tiende a concentrarlos

2. Estos definidos rara vez guardan relación con la temporalidad del cierre del capítulo.

3. Agradecemos al profesor José Manuel González Herrán el habernos facilitado copia del texto de su comunicación en el Congreso, «El individuo y la sociedad», celebrado en Santander, del 25 al 28 de noviembre de 2011. 
en núcleos coherentes de varias secuencias - las casas y las calles, la fábrica y sus alrededores, la ciudad y los extrarradios-, que sin embargo mantienen relaciones de interdependencia con el resto de la ciudad según avance el hilo argumental y como espacios recurrentes del pacto ficcional realista.

Asimismo desde el capítulo IX, cuando el entramado histórico empieza a cobrar protagonismo con sus referentes realistas, de 1868 a 1873, las marcas temporales diegéticas tienden a velarse o incluso a desaparecer en las introducciones de los capítulos. Éstas vuelven a reaparecer al final de la novela durante el período de embarazo siguiendo el ciclo de las estaciones de la naturaleza, como por ejemplo en «Las hojas caen»:

Aconteció que, cuando ya se aproximaba el otoño, la paralítica llamó a Amparo a la cabecera de su lecho, con tono y ademanes desusados, murmurando sordamente:

-Acércate aquí, anda.

Amparo se acercó con la cabeza baja. La madre extendió la mano, le cogió violentamente la barbilla para que alzase el rostro, y con voz aguda y terrible gritó: $-i Y$ ahora? (cap. XXXIII: 239).

Los espacios, al contrario, se van diversificando con mayor celeridad en función de la intriga, del desfile de personajes y de las marcas históricas realistas que va insertando la novelista. En estos cuadros independientes, el tiempo ficticio interno no parece esencial para la escritora, porque las referencias históricas del todavía presente del lector y su imbricación en los espacios del devenir de los personajes salvaguardan el efecto de realidad. Es lo que ocurre, por ejemplo, en la apertura del capítulo «Un delito», cuya frase inicial reza: «Desde la venida de Amadeo I tenían las cigarreras de Marineda a quien echar la culpa de todos los males que afligían a la Fábrica» (cap. XXIX, 214). En estos casos, la introducción de la secuencia subraya el papel de los personajes, actantes en la intrahistoria de España (Sotelo Vázquez, 2002 y 2010: 3439). Asimismo, Emilia Pardo Bazán introduce referentes del presente de sus lectores coetáneos que permiten actualizar el texto intencionalmente como verosímil:

Más partido tenían en la Fábrica los periódicos locales que los de la Corte. Naturalmente, los locales exageraban la nota, recargaban el cuadro; sus títulos acostumbraban ser por este estilo: El Vigilante Federal, órgano de la democracia republicana federal-unionista; El Representante de la Juventud Democrática; El Faro Salvador del Pueblo Libre. Y como, aparte de algunas huecas generalidades del artículo de fondo, discurrían acerca de asuntos conocidos, era mucho mayor el interés que despertaban (cap. X, 105).

Los cambios de escenarios y ambientes se suceden a imagen de un fluir impreciso. En ocasiones, enlazan dos o tres capítulos en sentido de continuidad 
-escenas revolucionarias, caps. XXV-XXIX-, o introducen escenas, en especial las costumbristas, apoyándose en referentes socioculturales y religiosos que completan la dimensión temporal:

Extramuros, al pie de las fortificaciones de Marineda, celébrase todos los años una fiesta conocida por las Comiditas, fiesta peculiar y característica de las cigarreras, que aquel día sacan el fondo del cofre a relucir y disponen una colación más o menos suculenta para despacharla en el campo; campo mezquino, árido, donde sólo vegetan cardos borriqueros y ortigas» (cap. XXV, 190).

Estos cuadros en nada afectarían al pacto de ficción con sus lectores coetáneos, habituados al pintoresquismo costumbrista y a los tópicos románticos -ya estudiados al analizar el mitigado realismo de La Tribuna (González Herrán, 1975, 1988, 1989a, 1989b; Sotelo, 1998, 2002 y 2010)-, sobre todo porque Pardo Bazán los insertaba como pausas lógicas en el mundo dinámico de la estética realista. La sensación del fluir de la vida en las secuencias de escenarios fijos -como las costumbristas o las amorosas ${ }^{4}$ - no desaparece, porque la escritora alterna dichos capítulos con el puntual recorrido de Amparo por los espacios céntricos y públicos de la urbe $e^{5}$ y con el regreso a la fábrica ${ }^{6}$.

Funcionalmente, ya hemos adelantado algunos ejemplos, los referentes espaciales de los inicios de los capítulos son de gran eficacia narrativa y cohesionan las secuencias de modo realista. Pueden estar asociados a la dimensión temporal para introducir analepsis: «Tres años antes, la imposibilitada estaba sana y robusta y ganaba su vida en la Fábrica de Tabacos. Una noche de invierno fue a jabonar ropa blanca al lavadero público, sudó, volvió desabrigada y despertó tullida de las caderas» (cap. II, 57) y elipsis temporales:

Se ha mudado la decoración; ha pasado casi un año; corre el mes de enero. No llueve; el cielo está aborregado de nubes lívidas que presagian tormenta, y el viento costeño, redondo, giratorio como los ciclones, arremolina el polvo, los fragmentos de papel, los residuos de toda especie que deja la vida diaria en las calles de una ciudad (cap. IV, pág. 70);

4. Es lo que ocurre, pero en el desarrollo de los capítulos sobre las escenas amorosas, contramodelos del locus amoenus y del hortus conclusus. En ellas el tiempo histórico, como ha precisado el González Herrán transcurre de 1871, cuando en «febrero vio la aurora de aquel amor en un día clásico, el de la Candelaria» (Pardo Bazán 2002, pág. 203) a febrero de 1873. Pero, a su vez el tiempo diegético se ralentiza adaptándolo simbólicamente al del paso de las estaciones durante embarazo de Amparo, de primavera a invierno; o sea, de finales de mayo de 1872 a febrero de 1873 con el regreso al espacio inicial, su casa. Véanse los capítulos XXVII y XXXI-XXXII.

5. En los capítulos XXVIII, XXX, XXXIII, XXXV-XXXVIII.

6. En los capítulo XXIX, XXXIV-XXXV. 
Pardo Bazán reorienta en algunos casos el relato hacia la acción principal, tal como se aprecia en el siguiente párrafo: «En la calle de los Castros estaba Carmela, la encajerita, descolorida como siempre y ocupada en oír de boca de Amparo el relato de los sucesos de la víspera» (cap. XV, 139).

Aunque a lo largo de la novela los personajes nunca se desligan de los espacios que los determinan, tan pronto como el lector pueda reconocerlos, éstos pasan a ser meros escenarios más nominados que descritos. Es evidente que la concreción de los espacios habituales resulta poco operativa si de antemano quedaron delimitados y caracterizados en sus múltiples componentes sociales, económicos, ideológicos tanto literal como simbólicamente. Una vez cumplidas las funciones metonímicas, el espacio «rara vez añade información nueva. Con frecuencia, su misión es claramente enfática» (Zubiaurre, 2000: 22). Es lo que ocurre, por ejemplo, cuando los lugares son metonimia de los personajes y denotan cambios en sus vidas. Citemos como botón de muestra el cambio de estatus profesional de Amparo al mudarse de taller, al piso superior, para hacer cigarrillos (cap. XII: 209). El taller, antes cerrado, se abre ahora al entorno como bien describe el narrador merced a la tradicional y simbólica ventana: «Desde las ventanas del taller de cigarrillos se registraba hermosa vista de mar y país montañoso, y entraba sin tasa por ellas luz y aire. [...] Y los personajes armonizaban con la decoración». (cap. XI, 209). En sentido contrario, el cambio de escenario puede dar cuenta de la degradación del personaje, aun cuando sea moral, en el tradicional retorno a los orígenes: «Alguna que otra vez volvía Amparo a visitar su antigua calle...» (cap. XXVIII, 209).

Como muestran estos someros ejemplos, la funcionalidad con la que Emilia Pardo Bazán concibe la dimensión espacial en las introducciones de los capítulos refuerza la unión entre los componentes novelescos de La Tribuna ${ }^{7}$.

7. La riqueza del tratamiento del espacio, ya sea bajo aspectos estructurantes, temáticos o estilísticos no se agota aquí. Anotemos que si bien la fábrica es el centro neurálgico del activismo socio-político obrero en La Tribuna, Emilia Pardo Bazán nunca lo convierte en espacio exclusivo, sino que con maestría rompe su omnipresencia -y cualquier apariencia de esquema fijo-, volviendo al espacio público de sus alrededores, a la calles, al espacio privado de la casa o al íntimo del huerto amoroso. Merced a estos cambios de escenarios y de perspectivas espaciales, la escritora introduce nuevas dialécticas simbólicas, como las tradicionales oposiciones entre espacios abiertos y cerrados -casa, fábrica, ambiente de Marineda y de España-, entre espacios privados y de sociabilidad -casa frente a paseo, teatro, Círculos, paseo, playa, etc.-, entre los espacios colectivos frente a los privados -casa frente a fábrica, Casino Rojo y anfiteatro-, espacios todos ellos jerarquizados, verticales y horizontales, reproduciendo todo tipo de antagonismos -barrios de arriba y de abajo, emplazamientos en edificios públicos, apropiación del espacio urbano-. 
La consecución del pacto de ficción, su evolución y mantenimiento en sus numerosos capítulo-documento redunda constantemente en el afianzamiento de un mundo geográfico verosímil. Pese a la incardinación del espacio en su dimensión temporal o en su función determinista, no es el establecimiento de una cronología del devenir lo que le interesa a la escritora para «dar vida al análisis» (Bernardini, 2007: 160) o condicionar destinos, sino la creación una cartografía urbana estructurante, dinámica y significativa en la que han de habitar sus personajes en unos momentos de profunda inestabilidad política en España.

\section{BIBLIOGRAFÍA}

Álvarez MÉNDEZ, Natalia. Espacios narrativos, León, Servicio de publicaciones de la Universidad de León, 2002.

ÁlvAREZ MÉNDEZ, Natalia. «La dimensión espacial narrativa: La Tribuna, de Emilia Pardo Bazán», La Tribuna, 6 (2007), pp. 121-148.

BAQUeRO GOYANES, Mariano. La novela naturalista española: Emilia Pardo Bazán, Murcia, Secretariado de la Universidad de Murcia, 1986.

BERNARDI, Andrea. «Edición genética y estudio del prólogo y del epílogo inédito de La Tribuna de Emilia Pardo Bazán», La Tribuna, 6 (2007), pp. 149-167.

ClÉMESSY, Nelly, «De La cuestión palpitante a La Tribuna: Teoría y praxis de la novela en Emilia Pardo Bazán», en Yvan Lissorgues (ed). Realismo y naturalismo en España en la segunda mitad del siglo XIX, Ed. Barcelona, Anthropos, 1988, pp. 485-496.

Del Lungo, Andrea. Gli inizi difficili. Per una poetica dell'incipit romanzesco, Padova, Unipress, 1997.

Del Lungo, Andrea, Lincipit romanesque, Paris, Editions du Seuil, 2003.

DuBoIS, Jean. «Surcodage et protocole de lecture dans le roman naturaliste», Poétique, IV, 16 (1973), pp. 491-498

DUCHET, Claude. «Pour une sociocritique ou variations sur un incipit», Littérature, 1 (1971), pp. 5-14.

Duchet, Claude. «Idéologie de la mise en texte», La Pensée, 215 (1980), pp. 95-107.

GONZÁlez Arias, Francisca. Portrait of a woman as artist: Emilia Pardo Bazán and the modern novel in France and Spain, New York, Garland Pub., 1992.

GONZÁLEZ HERRÁN, José Manuel. [En prensa]. «Historia, ficción y biografía en La Tribuna (1883), de Pardo Bazán: Emilia y Amparo, entre 1867-1873», Congreso Internacional «El individuo y la sociedad», celebrado en Santander, del 25 al 28 de noviembre de 2011.

GonzÁlez HerRán, José Manuel. «La Tribuna, de Emilia Pardo Bazán y un posible modelo real de su protagonista», Ínsula, 346, septiembre 1975, págs. 17-18. 
GonzÁlez Herrán, José Manuel, «La Tribuna, de Emilia Pardo Bazán, entre romanticismo y naturalismo», en Yvan Lissorgues (ed). Realismo y naturalismo en España en la segunda mitad del siglo XIX, Ed. Barcelona, Anthropos, 1988, pp. 497-512.

GonZÁlez Herrán, José Manuel. «Estudio Introductorio» a Pardo Bazán, Emilia. La cuestión palpitante, Barcelona-Santiago de Compostela, 1989ª pp. 47-50.

GonZÁlez Herrán, José Manuel.. «Emilia Pardo Bazán y el Naturalismo», Ínsula, 514, (octubre 1989b), pp. 17-18.

GULLÓN, Germán. La novela del XIX: estudio sobre su evolución formal, Ámsterdam, Rodopi, 1990.

Gullón, Ricardo. Psicologías del autor y lógicas del personaje. Madrid. Taurus, 1979.

Jenny, Laurent. «La stratégie de la forme», Poétique, 29 (1976), pp. 257-267.

LEVY, Josette, «Emilia Pardo Bazán y el regionalismo gallego [continuación]», Boletín de la Real Academia Gallega, 339-344 (1959-1961), pp. 283-293.

Lotman, Yuri. Estructura del texto artístico, Madrid, Ediciones Istmo, 1988.

MATZAT, Wolfang (ed.). Espacios y discursos en la novela española del realismo a la actualidad. Madrid- Frankfurt am Main, Iberoamericana-Vervuert, 2007.

MORHANGE, Jean Louis. «Incipits narratifs: l'entrée du lecteur dans l'univers de la fiction», Poétique, 104 (noviembre, 1995), pp. 387-410.

PARdo BAZÁn, Emilia. [1883]. La Tribuna, ed. de Marisa Sotelo VÁZQuez, Madrid, Alianza, 2002.

PARDO BAZÁn, Emilia [1892]. «Ojeada retrospectiva a varias obras francesas de Daudet, Loti, Bourget, Huysmans, Rod y Barrés», Nuevo Teatro Crítico, reproducido en Obras Completas, ed. a cargo de Harry Kirby, III, Madrid, Aguilar, 1973, pp. 1056-1072.

PARDo BAZÁn, Emilia. La cuestión palpitante, ed. José Manuel GOnZÁlez HerRÁn, Barcelona, Anthropos, Universidade Santiago de Compostela, 1989.

PATiÑo Eirín, Cristina. «Aproximación a los prólogos de Emilia Pardo Bazán», Boletín de la Biblioteca de Menéndez Pelayo, 71 (enero-diciembre, 1995), pp.. 137-167.

PATIÑo Eirín, Cristina. Poética de la novela en la obra crítica de Emilia Pardo Bazán, Santiago de Compostela, Servicio de Publicaciones e Intercambio Científico, 1998.

Penas Varela, Ermitas. 'Clarín', crítico de Emilia Pardo Bazán, Santiago de Compostela, Universidade, 2003.

Penas Varela, Ermitas. 2006. «El espacio en los cuentos de Emilia Pardo Bazán» José Manuel González Herrán, Cristina Patiño Eirín, Ermitas Penas Varela, eds. Emilia Pardo Bazán: Los cuentos, Coruña, Real Academia Galega, pp. 169-173. 
SCANLON, Geraldine M. 1990. «Class and Gender in Pardo Bazán’s La Tribuna», Bulletin of Hispanic Studies, 67, 2, pp. 137-150.

Sotelo VÁzQUez, Marisa. 1998. «Emilia Pardo Bazán: entre el Romanticismo y el Realismo», en Luis F. Díaz Larios, Enrique Miralles, Del Romanticismo al Realismo, Barcelona, Universitat, pp. 429-442.

SOTElo VÁzQUeZ, Marisa. 2002. «Introducción», en Emilia PARdo BAZÁN. La Tribuna, Madrid, Alianza, pp. 7-43.

SOTElo VÁzQUEZ, Marisa. 2010. La cigarrera revolucionaria. La Tribuna de Emilia Pardo Bazán, Madrid, Ediciones del Orto-Universidad de Minnesota.

VArela Jácome, Benito. 1973. Estructuras novelísticas de Emilia Pardo Bazán, Santiago de Compostela, CSIC, Cuadernos de estudios gallegos, Anejo XXII, 1973.

VillanueVA, Darío. 1992 y 2004. Teorías del realismo literario, Madrid. Instituto de España, Espasa-Calpe y Biblioteca Nueva.

Zubiaurre, María Teresa, 2000. El espacio en la novela realista. Paisajes, miniaturas, perspectivas, México, Fondo de Cultura Económica.

Fecha de recepción: 08-01-2012

Fecha de aceptación: 15-05-2012 